\title{
Pollination and CPPU Treatment Increase Endogenous IAA and Decrease Endogenous ABA in Muskmelons during Early Development
}

\author{
Yasuyoshi Hayata, Xin-Xian Li, and Yutaka Osajima \\ School of Bioresources, Hiroshima Prefectural University, Shobara, Hiroshima 727-0023, Japan
}

\begin{abstract}
AdDitional INDEX words. Cucumis melo, fruit growth and development, fruit set, phytohormone
Abstract. An investigation was conducted to determine how pollination and CPPU treatment influence endogenous IAA and ABA content in netted muskmelon [Cucumis melo L. (Reticulatus Group) 'Crest Earl's'], and to clarify their roles in fruit set and development in relation to these endogenous plant hormones. CPPU treatment at anthesis significantly increased the fresh weight of ovaries, whether the flowers were pollinated or not, but from 6 days after anthesis (DAA) the growth rate in the nonpollinated + CPPU treatment tended to be lower than the growth rates in the pollination treatment plots. Ovaries of nonpollinated flowers not treated with CPPU failed to grow and turned brown within 4 DAA. IAA content in the placenta of fruit from pollinated flowers increased rapidly from the day of anthesis to 2 DAA and remained at relatively high levels. IAA content in the placenta of parthenocarpic fruit induced to develop by CPPU treatment was lower than that of fruit from pollinated flowers but the pattern was almost the same as that in fruit of pollinated flowers. Conversely, IAA content in the placenta of fruit from nonpollinated flowers not treated with CPPU decreased sharply after anthesis. IAA content in the mesocarp of CPPU-treated fruit, whether or not the flowers were pollinated, increased significantly from the day of anthesis to 2 DAA, then decreased to almost the same level as that of the pollination-only treatment by 10 DAA, while the IAA content of nonpollinated CPPU-treated fruit declined even further. IAA content in the mesocarp of fruit from nonpollinated flowers not treated with CPPU decreased sharply. ABA contents in both the placenta and mesocarp of muskmelon that would set decreased after anthesis while the ABA content of muskmelon that would not set increased rapidly. Results suggest that pollination and CPPU treatment increased endogenous IAA content and decreased endogenous ABA content to promote the set and growth of fruit during early development. Chemical names used: [1-(2-chloro-4-pyridyl)-3-phenylurea] (CPPU); indole-3-acetic acid (IAA); abscisic acid (ABA).
\end{abstract}

Fruit grow most rapidly during the early stages following anthesis, and whether plants will retain or shed these fruit is determined at this time. Pollination and fertilization are the main predictors of fruit growth during these early stages and it has been suggested that seed-produced auxin is involved in fruit set and development (Weaver, 1972). This view is supported by reports showing that IAA content in the seeds is higher than that in the mesocarp of strawberry (Fragaria $\times$ ananassa Duchesne) (Nitsch, 1950), peach [Prunus persica L. Batsch (Peach Group)] (Miller and Walsh, 1990) and tomato (Lycoperisicon esculentum Mill.) (Hocher et al., 1992).

Effects of plant bioregulators on fruit set of muskmelon (Cucumis melo L.) has been investigated and auxin-derivative plant hormones, such as $p$-chlorophenoxyacetic acid, 2,4-dichlorophenoxyacetic acid, and naphthaleneacetic acid, as well as chemicals with cytokinin activity such as 6-benzylaminopurine and CPPU, all promote fruit set (Hayata et al., 2000). CPPU promotes fruit set even under conditions that are unfavorable for pollination and fertilization. However, few studies have investigated the relationship between fruit set of muskmelon and endogenous growth substances. Xu et al. (1989) reported that IAA content increased during the period when fruit grew rapidly in the early growth stage. Although Lingle and Dunlap (1991) reported that IAA levels were the highest at $2 \mathrm{~d}$ before anthesis, they also showed that IAA levels increased after anthesis to $2 \mathrm{~d}$ after anthesis (DAA), and that there were some increases in free IAA, esterified and amide forms of IAA during the maturing period. On the other hand, Lee et al. (1997) reported that IAA content in the

Received for publication 4 June 2001. Accepted for publication 24 July 2002. We are grateful to Keiko Koshita of the National Institute of Fruit Tree Science for helpful advice and support. ovary did not fluctuate much during early development. Although IAA appears to be an important plant hormone in the growth of muskmelons, changes in endogenous IAA activity in muskmelons during development are inconsistent among those studies. Research on ABA content during early development of muskmelons is limited, with one report that $\mathrm{ABA}$ decreased during development (Xu et al., 1989). Therefore, the following study was conducted to investigate how pollination and CPPU treatment at anthesis influence fruit set, growth, and endogenous IAA and ABA levels in muskmelons.

\section{Materials and Methods}

Plant material and culture. Seedlings of 'Crest Earl's' netted muskmelon [Cucumis melo (Reticulatus Group)] were transplanted $45 \mathrm{~cm}$ apart in two rows $(1.2 \mathrm{~m}$ wide $\times 17 \mathrm{~m}$ long, two beds) in a heated greenhouse at Hiroshima Prefectural University Hiroshima, Japan, on 1 June 1999. The plants were grown under natural photoperiod and irradiance from 1 June through 26 Sept. Air temperature was maintained between 18 and $28^{\circ} \mathrm{C}$. The soil in the beds was a sandy loam with $2 \%$ organic matter. Soil $\mathrm{pH}$ was 6.5. Irrigation of the beds was regulated automatically by a tensionmeter (DM-8P Melon; Takemura Electric Works Ltd., Tokyo). Fertilizer was applied twice. The first application was a preplant broadcast application of $900 \mathrm{~kg} \cdot \mathrm{ha}^{-1}$ of $14 \mathrm{~N}-14 \mathrm{P}-36 \mathrm{~K}$; the second application was a sidedress application at anthesis of $\mathrm{N}$ at $326 \mathrm{~kg} \cdot \mathrm{ha}^{-1}$. Each lateral shoot between the 13th and 15th nodes of the main shoot was cut above the 2nd node; and female flowers adhering to the first nodes of the lateral shoots were used in this experiment. Other lateral shoots were removed. The main shoots were trained upwards and topped at the 24th node.

TreatMenTs. Forty plants were assigned randomly to each of 
four treatment groups and treatments were applied as follows: female flowers were hand-pollinated at anthesis without any other treatment $(\mathrm{P})$; female flowers were hand-pollinated and sprayed with a solution of CPPU at $20 \mathrm{mg} \cdot \mathrm{L}^{-1}$ (Sigma Chemical Co., St. Louis) at anthesis (PC); female flowers covered with paper bags from the day before anthesis were not pollinated $(\mathrm{E})$; and the nonpollinated female flowers were sprayed with a solution of CPPU at $20 \mathrm{mg} \cdot \mathrm{L}^{-1}$ at anthesis (EC). The paper bags were removed 3 DAA. Fruit in all treatments were sampled the day before anthesis and on 0,2, 4, 6, and 10 DAA. Each harvested fruit was placed immediately in a cold room $\left(4^{\circ} \mathrm{C}\right)$ where it was sliced horizontally and the slices divided vertically into four sections. The placenta (containing ovule) and the mesocarp of each fruit were sampled and stored at $-80^{\circ} \mathrm{C}$ until analysis.

IAA AND ABA ANALYSES. IAA and ABA contents were measured by gas chromatography-mass spectrometry-selected ion monitoring (GC-MS-SIM) according to a modified procedure of Kojima et al. (1999). Ten grams of frozen sample and $100 \mathrm{~mL}$ of $80 \%(\mathrm{v} / \mathrm{v})$ cold methanol containing butylated hydroxytoluene at $20 \mathrm{mg} \cdot \mathrm{L}^{-1}$ were homogenized for $1 \mathrm{~min}$ in a GLC homogenizer (Yamato Scientific Co. Ltd., Tokyo) at 30,000 rpm. The homogenate was centrifuged at $13,000 g_{\mathrm{n}}$ for $10 \mathrm{~min}$, and the residue extracted once again. Supernatants were pooled, ${ }^{13} \mathrm{C}_{6}$-IAA (Kojima, 1995) and [3',5',5',7',7',7'-2 $\mathrm{H}_{6}$ ]ABA [purity 99\%, Shoko Co., Ltd., Tokyo, synthesized according to the method of Rivier et al. (1977)] were added as internal standards, and the mixture concentrated at $35^{\circ} \mathrm{C}$ to the aqueous phase using a rotary evaporator. The aqueous phase was filtered through membrane filters (3.0, 1.0, and $0.2 \mu \mathrm{m}$, Nihon Millipore Ltd., Tokyo), adjusted to pH 8.5 with $0.5 \mathrm{M} \mathrm{K}_{2} \mathrm{HPO}_{4}$, and partitioned twice against petroleum ether. The aqueous fraction was acidified to $\mathrm{pH} 2.8$ with 6 $\mathrm{N}$ phosphoric acid and partitioned three times against ethyl acetate. The pooled ethyl acetate fraction was evaporated to 20 $\mathrm{mL}$ and partitioned three times against a $\mathrm{NaHCO}_{3}(\mathrm{pH} 8.0)$ solution. The aqueous fraction was acidified to $\mathrm{pH} 2.8$ with $6 \mathrm{~N}$

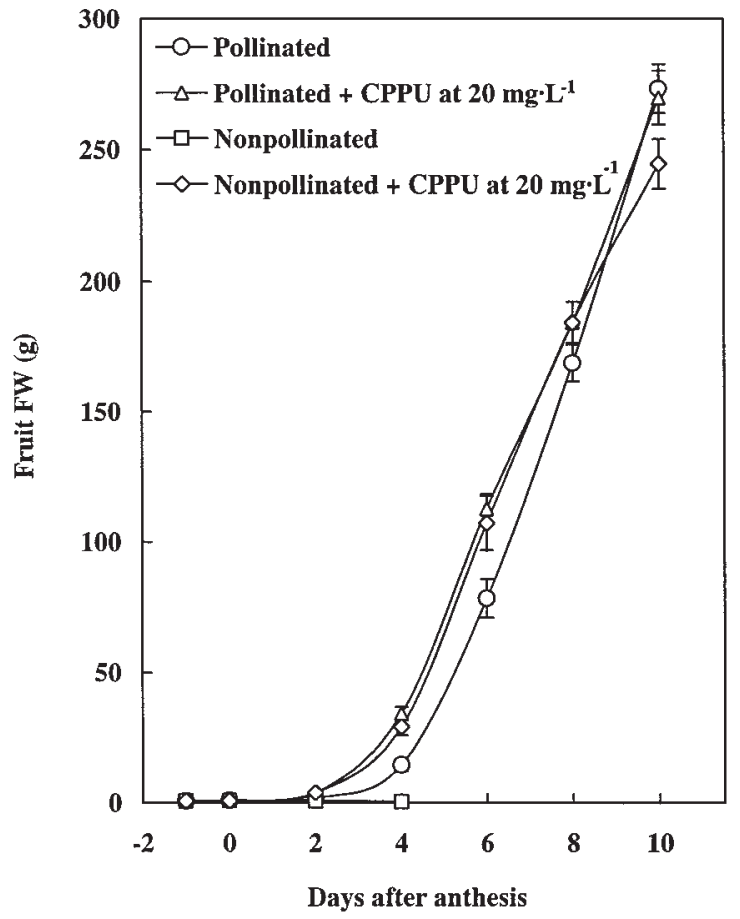

Fig. 1. Effects of pollination and CPPU treatment on fresh weight of 'Crest Earl's' muskmelon fruit during the early growth stage. Each symbol represents the mean $(n=10) \pm$ SE. phosphoric acid and again partitioned three times against ethyl acetate. The ethyl acetate fraction was evaporated, and the residue was dissolved in $1 \mathrm{~mL} \mathrm{80 \%} \mathrm{methanol} \mathrm{and} \mathrm{purified} \mathrm{using} \mathrm{the} \mathrm{Sep-}$ Pak C18 cartridge (Waters Corp., Milford, Mass.). The extract was fractionated with a Shimadzu-10A high-performance liquid chromatography (HPLC) system (Shimadzu Co., Ltd., Kyoto, Japan) equipped with a Shimadzu SPD-10A UV-VIS ultraviolet spectrophotometer at $254 \mathrm{~nm}$. The HPLC column was a Shimpack CLC-ODS $(150 \times 6.0 \mathrm{~mm}$ i.d., Shimadzu Co., Ltd.) maintained at $35{ }^{\circ} \mathrm{C}$ with a $40 \%$ methanol solution adjusted to $\mathrm{pH} 3.5$ with acetic acid at a flow rate of $1 \mathrm{~mL} \cdot \mathrm{min}^{-1}$. The IAA and ABA fractions were dried in vacuo and methylated by adding an excess of diazomethane in diethyl ether. The methylated IAA sample was dried with $\mathrm{N}_{2}$ and then trimethylsilylated with $20 \mu \mathrm{L}$ of Nmethyl-N-trimethylsilyl-trifluoroacetamide (MSTFA, Pierce Chemicals Co., Rockford, Ill.). The methylated ABA and the trimethylsilylated IAA were dissolved with $50 \mu \mathrm{L}$ methanol and injected into a QP5050 GC-MS system (Shimadzu Co., Ltd.) with selected ion monitoring, respectively. A DB-1 (J \& W Scientific, Folsom, Calif.) capillary column $(30 \mathrm{~m} \times 0.32 \mathrm{~mm}$ i.d. $\times 0.25 \mu \mathrm{m}$ film thickness) was coupled directly to the ion-source interface, the temperature of which was $250{ }^{\circ} \mathrm{C}$, and the column temperature was maintained at $50^{\circ} \mathrm{C}$ for $2 \mathrm{~min}$, then increased at $30{ }^{\circ} \mathrm{C} / \mathrm{min}$ to $170{ }^{\circ} \mathrm{C}$, which was maintained for $2 \mathrm{~min}$, and then at $10^{\circ} \mathrm{C} / \mathrm{min}$ to $250^{\circ} \mathrm{C}$. The helium carrier gas inlet pressure was $50 \mathrm{kPa}$. IAA and ABA contents were calculated by monitoring target ion $\mathrm{m} / \mathrm{z} 202 / 208$ and reference ion $\mathrm{m} / \mathrm{z} 261 / 267$, and target ion $\mathrm{m} / \mathrm{z}$ 190/194 and reference ion $\mathrm{m} / \mathrm{z}$ 162/166, respectively.

DAtA ANALYSIS. Means and SE values were calculated based on the data obtained from 10 replications for fresh weight $(\mathrm{FW})$ and

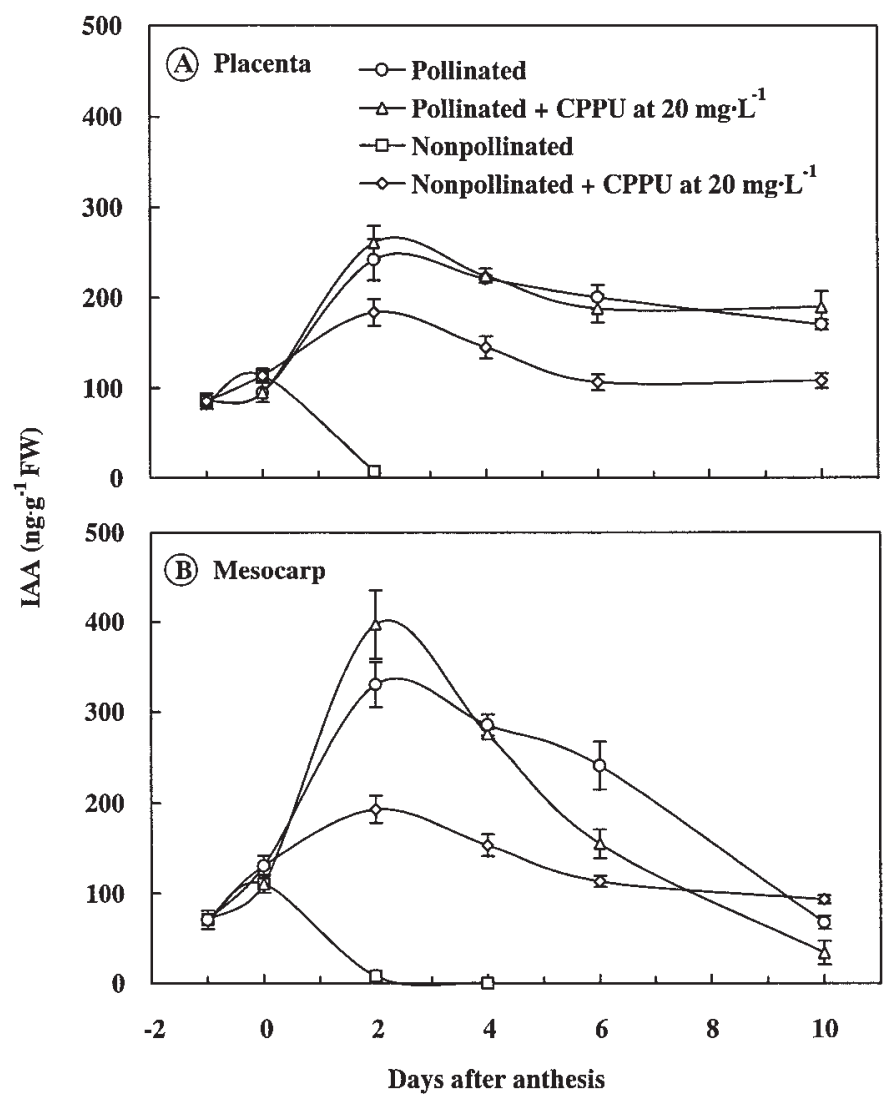

Fig 2. Effect of pollination and CPPU treatment on the IAA content of (A) placenta and (B) mesocarp of 'Crest Earl's' muskmelon fruit during the early growth stage. Each symbol represents the mean $(n=3) \pm \mathrm{SE}$. 
three replications for IAA and ABA analyses by each sampling time.

\section{Results and Discussion}

CPPU treatment at anthesis significantly increased fruit FW whether flowers were pollinated or not, and at 2 DAA the FW increased 2-fold compared with treatment P. Thereafter, fruit growth rate in treatment $\mathrm{P}$ increased, and $\mathrm{FW}$ became the same as that in treatment $\mathrm{PC}$ at $10 \mathrm{DAA}$, while $\mathrm{FW}$ in treatment $\mathrm{EC}$ showed the reverse pattern (Fig. 1). These results are consistent with our previous finding (Hayata et al., 2000) and confirm the promoting effect of CPPU on growth of young muskmelons. Nonpollinated fruit failed to grow; instead, FW decreased by $20 \%$ by 2 DAA, the ovary turned yellow and then brown by 4 DAA.

IAA content in the placental tissues of the muskmelons was $85.5 \mathrm{ng} \cdot \mathrm{g}^{-1} \mathrm{FW}$ on the day before anthesis, and increased thereafter, whether the flower was pollinated or not (Fig. 2A). In both treatments $\mathrm{P}$ and $\mathrm{PC}$, IAA content in the placenta increased rapidly from the day of anthesis to $2 \mathrm{DAA}$ and was maintained at high levels even though it declined slightly thereafter; IAA content in the placenta of parthenocarpic fruit induced by CPPU was lower than the IAA contents of pollinated fruit, but showed almost the same changes as in the pollinated fruit. IAA content in the placenta of treatment $\mathrm{E}$ decreased dramatically, and became undetectable by 2 DAA.

IAA content in the mesocarp of CPPU-treated fruit increased more than the fruit in the $\mathrm{P}$ treatment group from the day of anthesis until 2 DAA, regardless of pollination (Fig. 2B). There-

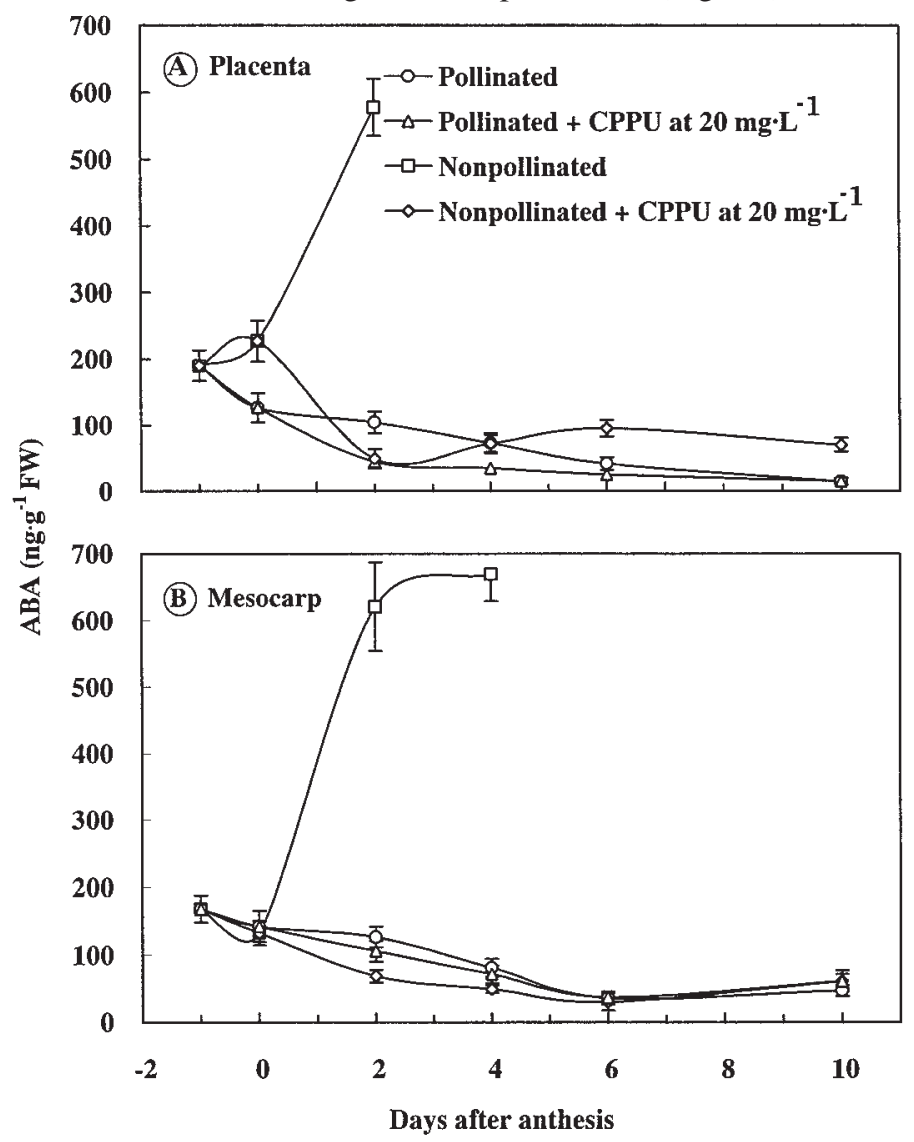

Fig 3. Effect of pollination and CPPU treatment on the ABA content of (A) placenta and (B) mesocarp of 'Crest Earl's' muskmelon fruit during the early growth stage. Each symbol represents the mean $(n=3) \pm$ SE. after, however, IAA content decreased; IAA levels in the PC treatment group decreased to almost the same as the levels in the $\mathrm{P}$ group, and IAA levels in the EC treatment group became lower than those in both the $\mathrm{PC}$ and $\mathrm{P}$ groups $\left(34 \mathrm{ng} \cdot \mathrm{g}^{-1} \mathrm{FW}\right)$. IAA content in the mesocarp of the E treatment group decreased as rapidly as that in the placenta, and became undetectable by 2 DAA; that is, changes in IAA content in the mesocarp of nonpollinated fruit were similar to those in the placenta. In addition, since there was a concentration gradient in IAA from the placenta to the mesocarp, IAA levels are presumed to move along a gradient. Our previous observation supports this speculation: a concentration gradient in IAA moved along from the normal seeds to the placenta and toward the mesocarp (Li et al., 2002).

Gustafson (1939) reported that auxin was a key substance for fruit set, based on his observations that IAA content in the ovary of parthenocarpic grape (Vitis labrusca L.), orange (Citrus aurantium L.), and lemon (Citrus limon Burm.f.) was higher than IAA content in nonparthenocarpic ovaries at anthesis. Takeno and Ise (1992) reported that IAA content in the ovary of parthenocarpic cucumber (Cucumis sativus L.) was three times higher than in cucumber that dropped fruit several days after anthesis. Since we observed that pollination increased IAA content in the placenta and ovary of netted muskmelon, IAA appears to be involved in fruit set. This is supported by the observation that application of CPPU, a fruit set promoting treatment for muskmelon, increased IAA content. Thus, it is appears that parthenocarpy induced by CPPU and the promotive effect of CPPU on fruit set are closely associated with biosynthesis of endogenous IAA, and it is clear that the promotive effect of CPPU on biosynthesis of IAA is temporary, occurring only at the time of treatment. There have been some reports about IAA levels in the ovary of melon at anthesis. Lingle and Dunlap (1991) showed that although the highest IAA level was reached before anthesis, IAA levels increased again after anthesis to 2 DAA, and Xu et al. (1989) reported that IAA levels increased after pollination. These increasing patterns coincide with our results. Furthermore, CPPU treatment increased the growth of the ovary at anthesis when cell division was still occurring (Masuda and Hayashi, 1959); that is, CPPU promoted cell division using its own active cytokinin (Takahashi et al., 1978). It is also possible that CPPU promoted biosynthesis of IAA, which is involved in cell enlargement, resulting in enhancement of growth.

Baldi et al. (1989) reported that under alkaline extraction conditions, IAA ester was hydrolyzed to free IAA. However, they showed that significant hydrolysis occurred only after a 2-h exposure to $\mathrm{pH} 9.0$ or above. Since our samples were exposed to mild alkaline conditions for $<1 \mathrm{~h}$ during extraction, hydrolysis of IAA-ester would have been minimal. Additionally, it was apparent that there were differences in IAA levels between the treatments.

Endogenous $\mathrm{ABA}$ content in the mesocarp and placenta of muskmelons was $\approx 180$ to $190 \mathrm{ng} \cdot \mathrm{g}^{-1} \mathrm{FW}$ at anthesis, and ABA levels of all treatment groups except $E$ decreased gradually by 6 DAA, and thereafter maintained almost the same level (Fig. 3A). This declining pattern of ABA in fruit agrees with findings of $\mathrm{Xu}$ et al. (1989). On the other hand, ABA content in treatment E increased rapidly from the day of anthesis, and at 2 DAA it was three times higher than that of the day before anthesis: $578 \mathrm{ng} \cdot \mathrm{g}^{-}$ ${ }^{1} \mathrm{FW}$ in the placenta (Fig. 3A), and $620 \mathrm{ng} \cdot \mathrm{g}^{-1} \mathrm{FW}$ in the mesocarp (Fig. 3B). In addition, previous studies showed the same declining pattern of ABA content in satsuma mandarin [Citrus unshiu (Mak) Maric.] (Kojima et al., 1996), persimmon (Diospyros kaki 
Thunb.) (Kojima et al., 1999), strawberry (Archbold and Dennis, 1984), and pear (Pyrus communis L.) (Gil et al., 1972). It may be that fruit set in various fruits, including muskmelon, requires a decrease of ABA content.

Results herein demonstrate that pollination and CPPU treatment increase endogenous IAA content of muskmelons and decrease endogenous ABA content at fruit set. The presence of high IAA content and low ABA content may be closely related to fruit set and growth during the early growth stages. Moreover, it appears that CPPU not only operates directly as a cytokinin but also induces parthenocarpy and promotes growth in the early growth stage periods by increasing endogenous IAA in muskmelons.

\section{Literature Cited}

Archbold, D.D. and J.F.G. Dennis. 1984. Quantification of free ABA and free and conjugated IAA in strawberry achene and receptacle tissues during fruit development. J. Amer. Soc. Hort. Sci. 109:330-335.

Baldi, G.B., R.B. Maher, and J.D. Cohen. 1989. Hydrolysis of indole-3acetic acid esters exposed to mild alkaline conditions. Plant Physiol. 91:9-12.

Gil, G.F., G.C. Martin, and W.H. Griggs. 1972. Fruit set and development in the pear: Extractable endogenous hormones in parthenocarpic and seeded fruit. J. Amer. Soc. Hort. Sci. 97:731-735.

Gustafson, F.G. 1939. The cause of natural parthenocarpy. Amer. J. Bot. 26:135-138.

Hayata, Y., Y. Niimi, K. Inoue, and S. Kondo. 2000. CPPU and BA, with and without pollination affect set, growth and quality of muskmelon fruit (Cucumis melo L.). HortScience 35:868-870.

Hocher, V., B. Sotta, R. Maldiney, M. Bonnet, and E. Miginiac. 1992. Changes in indole-3-acetic acid levels during tomato (Lycopersicon esculentum Mill.) seed development. Plant Cell Rpt. 11:253-256.

Kojima, K. 1995. Simultaneous measurement of ABA, IAA and GAs in citrus-Role of ABA in relation to sink ability. Jpn. Agr. Res. Q. 29:179-185.
Kojima, K., K. Shiozaki, Y. Koshita, and M. Ishida. 1999. Changes of endogenous levels of ABA, IAA and GA-like substances in fruitlet of parthenocarpic persimmon. J. Jpn. Soc. Hort. Sci. 68:242-247.

Kojima, K., M. Yamamoto, A. Goto, and R. Matsumoto. 1996. Changes in $\mathrm{ABA}$, IAA and GAs contents in reproductive organs of satsuma mandarin. J. Jpn. Soc. Hort. Sci. 65:237-243.

Lee, T.H., T. Kato, Y. Kanayama, H. Ohno, K. Takeno, and S. Yamaki. 1997. The role of indole-3-acetic acid and acid invertase in the development of melon (Cucumis melo L. cv. Prince) fruit. J. Jpn. Soc. Hort. Sci. 65:723-729.

Li, X.X., Y. Hayata, and Y. Osajima. 2002. p-CPA increases the endogenous IAA content of parthenocarpic muskmelon fruit. Plant Growth Regulat. (in press).

Lingle, S.E. and J.R. Dunlap. 1991. Sucrose metabolism and IAA and ethylene production in muskmelon ovaries. J. Plant Growth Regulat. 10:167-171.

Masuda, T. and K. Hayashi. 1959. Studies on the thickening growth of melon fruits. (in Japanese with English summary). Bul. Res. Inst. System Hort. Fac. Agr., Okayama Univ. 14:72-79.

Miller, A.N. and C.S. Walsh. 1990. Indole-3-acetic acid concentration and ethylene evolution during early development in peach. Plant Growth Regulat. 9:37-46.

Nitsch, J.P. 1950. Growth and morphogenesis of the strawberry as related to auxin. Amer. J. Bot. 37:211-215.

Takahashi, S., K. Shudo, T. Okamoto, K. Yamada, and Y. Isogai. 1978. Cytokinin activity of $n$-phenyl- $n$ '-(4-pyridyl)urea derivatives. Phytochemistry 17:1201-1207.

Takeno, C. and H. Ise. 1992. Parthenocarpic fruit set and endogenous indole-3-acetic acid content in ovary of Cucumis sativus L. J. Jpn. Soc. Hort. Sci. 60:941-946.

Weaver, R.J. 1972. Fruit set and development, p. 223-237. In: R.J. Weaver (ed.). Plant growth substances in agriculture. W. H. Freeman and Co., San Francisco.

Xu, X., T. Kato, Y. Fukumoto, Y. Nakajima, and L. Zhong. 1989. Changes in endogenous hormone levels of watermelon and muskmelon fruits during development. (in Japanese). Bul. Res. Inst. System Hort. Fac. Agr. Kochi Univ. 6:15-21. 